\title{
Evaluation of particle agglutination assay for the rapid diagnosis of Japanese encephalitis infection
}

\section{Pant KP, ${ }^{1,2}$ Pun R, ${ }^{2}$ Khanal SR, ${ }^{1}$ Lekhak B, ${ }^{2}$ Shah $Y,{ }^{3,4}$ Shardulendra SP,5 Kshetri $R^{, 6}$ Pandey BD ${ }^{4,7^{*}}$}

\footnotetext{
1Department of Microbiology, Siddhanath Science Campus Mahendranagar, Kanchanpur, Nepal, ${ }^{2}$ Central Department of Microbiology, Tribhuvan University, Kirtipur, Kathmandu, Nepal, ${ }^{3}$ Kathmandu College of Science and Technology, Kalimati, Kathmandu, Nepal, ${ }^{4}$ Everest International Clinic and Research Centre, Kalanki, Kathmandu, Nepal, ${ }^{5}$ National College, Khusibu, Kathmandu, Nepal, ${ }^{6}$ Bajhang District Hospital , Bajhang, Nepal, ${ }^{7}$ Sukraraj Tropical and Infectious Diseases Hospital, Teku, Nepal
}

${ }^{*}$ Correspondence to: Dr. Basu Dev Pandey, Everest International Clinic and Research Centre, GPO Box 9045, Kalanki, Kathmandu, Nepal, email: drbasupandey@gmail.com, Tel. No.: (+977)9851065451

\begin{abstract}
INTRODUCTION: Japanese encephalitis (JE) is a disease of rural agricultural areas in the Terai regions of Nepal. The aim of the study was to compare particle agglutination assay (PA) with IgM capture ELISA.

MATERIALS AND METHODS: The descriptive crosssectional study was conducted from August 2006 to September 2008. A total of 552 serum samples were collected from patients clinically diagnosed as acute encephalitis syndrome (AES) or viral fever in Tribhuvan University Teaching Hospital (TUTH) in Kathmandu, Lumbini Zonal Hospital (LZH) in Rupandehi and Bheri Zonal Hospital (BZH) in Banke districts. The samples were tested for Japanese encephalitis virus (JEV) specific IgM by two serological methods, IgM capture ELISA and PA.
\end{abstract}

RESULTS: Among 552 samples, 258 samples were positive by PA and 205 were positive by IgM capture ELISA. The overall seroprevalence was $46.7 \%$ and $37.1 \%$ by the PA and IgM ELISA respectively. Two hundred fifty eight samples $(47.7 \%)$ were positive for anti-JE IgM by PA assay and 200 samples $(77.5 \%)$ of the 258 PA IgMpositive samples were also IgM positive for anti-JE IgM by IgM-capture ELISA. Thus, PA assay had a sensitivity of $97.5 \%$ and specificity of $83.3 \%$ in comparison with IgM-capture ELISA. A positive predictive value of 0.77 and negative predictive value of 0.98 was observed with PA in comparison with IgM-capture ELISA.

CONCULSIONS: The result from PA was highly compatible with IgM capture ELISA. Both sensitivity and specificity of PA was acceptable in comparison with IgM-capture ELISA.

KEY WORDS: Japanese encephalitis, Particle Agglutination Assay, Enzyme linked immunosorbent assay

Article submitted 18 July. Reviewed 20 August. Author correction 28 August. Final version accepted 16 September 2012 


\section{INTRODUCTION}

Japanese encephalitis (JE) is an arboborne infection of humans caused by Japanese encephalitis virus (JEV). JE results in a zoonotic transmission cycle between pigs or birds and mosquitoes. JEV spreads to humans through the bite of JEV infected mosquitoes. Culex mosquitoes, mainly Culex tritaeniorhyncus is the vector responsible for the disease. ${ }^{1}$ In other way, JE is principally a disease of rural agricultural areas, where vector mosquitoes live in close association with the main vertebrate hosts. $^{2} \mathrm{JE}$ is generally diagnosed on the basis of clinical symptoms in the rural area of Asia including Nepal. JEV is rarely isolated from clinical specimens because of short and low levels of viraemia and rapid development of neutralizing antibodies. ${ }^{3}$ The laboratory diagnosis of JE, therefore, usually relies on serology which is done by detecting specific antibodies. IgM capture ELISA is sensitive and specific however, requires sophisticated equipment. 3,5

A simple particle agglutination (PA) assay has been developed for detecting JEV IgM. ${ }^{5,6}$ The PA assay is simple which does not require sophisticated facilities and equipments. Furthermore, the kit is inexpensive and stable even at high temperature. ${ }^{5}$ In the present study, we evaluate the ability of PA assay for the diagnosis of JE in developing countries like Nepal. We compared the results of PA assay with IgM capture ELISA.

\section{MATERIALS AND METHODS}

This was a cross-sectional study conducted from August 2006 to September 2008. A total of 552 serum samples were collected from patients clinically diagnosed as AES or viral fever in Tribhuvan University Teaching Hospital (TUTH) in Kathmandu, Lumbini Zonal Hospital (LZH) in Rupandehi and Bheri Zonal Hospital (BZH) in Banke districts. Before collecting blood specimens, demographic information was recorded and informed consent was obtained from each patient or respective guardian. Serum samples were stored at $2-8^{\circ} \mathrm{C}$ until transported to the Everest International Clinic and Research Centre, Kalanki, Kathmandu. Serum Samples were stored at $-20^{\circ} \mathrm{C}$ until tested.

IgM capture ELISA: The PanBio JE IgM capture ELISA was performed according to the manufacturer's instruction. The required numbers of the wells were determined for the assay. Ten micro liter of antigen was mixed with $2.5 \mathrm{ml}$ of antigen diluents. The required volume of diluted antigen was removed from the mixture. The equal volume of MAb tracer was added to diluted antigen, mixed gently and left at room temperature (20$25^{\circ} \mathrm{C}$ ). Immediately $100 \mu \mathrm{l}$ of diluted serum (1:100) was added into wells coated with anti-human IgM. The plate was incubated at $37^{\circ} \mathrm{C}$ for 30 minutes. Then the plate was washed for six times with diluted wash buffer. $100 \mu \mathrm{l}$ of Ag-MAb tracer was added to the wells. Again the plate was incubated at $37^{\circ} \mathrm{C}$ for 30 minutes. The plate was again washed for six times with diluted wash buffer. One hundred micro liter of TMB was added to each well. Incubation was done at $20-25^{\circ} \mathrm{C}$ for 10 minutes. Finally $100 \mu \mathrm{l}$ of stop solution was added and observed the change in color pattern. Within 30 minutes, the absorbance of each well was taken at a wavelength of $450 \mathrm{~nm}$ with a reference filter of 600$650 \mathrm{~nm}$ by using ELISA Reader.

Detection of anti-JEV IgM by IgM detection particle agglutination assay: The PENTAX Hapalyse anti-JEV IgM antibody detection PA assay was performed according to the manufacturer's instruction. Fifty $\mu \mathrm{l}$ diluted serum samples (1:100) was added in anti-human IgM coated 96-well microplates, and reacted for 30 minutes at room temperature. Serum samples were removed from the wells and wells were washed three times with wash buffer. One hundred $\mu$ l of JEV antigen coated, hydroxyapatite-coated nylon (Ha-Ny) beads were added to the wells and left for one hour at room temperature. When the Ha-Ny beads formed a button pattern at the bottom of the well, the reaction was defined as negative. Adhesion of Ha-Ny beads on the wall of the well was defined as positive reaction.

Ethical Committee approval: Approval was taken from the institutional ethics committee and also ethical clearance was taken from Nepal Health Research Council for prior to study.

Statistical Analysis: The collected data was analyzed to find out the JE IgM positive rate among patients clinically diagnosed AES and viral fever and comparison of PA with IgM capture ELISA. The collected data was analyzed using WIN PEPI software (version 7.9, November 24, 2008). Chisquare value and $p$ value were determined to find out whether the findings were statistically significant or not.

\section{RESULTS}

The 552 serum samples collected from the patients 
Table 1. JE IgM positive rate among patients clinically diagnosed AES and viral fever

\begin{tabular}{lccccc}
\hline \multirow{2}{*}{ Clinical Diagnosis } & \multicolumn{4}{c}{ JE IgM-Positive } \\
\cline { 2 - 6 } & Numbers & Positive & $\%$ & IgM ELISA & Positive \\
\hline AES & 519 & 245 & 47.2 & 194 & 37.4 \\
Viral fever & 33 & 13 & 39.4 & 11 & 33.3 \\
Total & 552 & 258 & 46.7 & 205 & 37.1 \\
\hline
\end{tabular}

Table 2. Comparison of PA with IgM capture ELISA

\begin{tabular}{lcccc}
\hline & & \multicolumn{2}{c}{ IgM capture ELISA } & Total \\
\cline { 3 - 4 } & & Positive & Negative & \\
\hline Particle agglutination assay* & Positive & 200 & 58 & 258 \\
& Negative & 5 & 289 & 294 \\
Total & & 205 & 347 & 552 \\
\hline * & & & \\
\end{tabular}

*sensitivity was $97.5 \%$ and specificity was $83.3 \%$

with the clinical diagnosis of AES and Viral fever from the three different hospitals of Nepal were tested for JEV specific IgM-capture PA and ELISA. Of the total samples, were clinical suspects of AES and 33 samples were clinical suspects of viral fever. Of 519 AES cases, 245 (47.2\%) and 194 (37.4\%) were IgM positive by the PA assay and IgM ELISA respectively. Out of 33 viral fever cases, 13 (39.4\%) and 11 (33.3\%) were IgM positive by the PA assay and IgM ELISA respectively. The overall seroprevalence was $46.7 \%$ and $37.1 \%$ by the PA assay and IgM ELISA respectively (Table 1). The sensitivity of PA was $97.5 \%$ and specificity was 83.3\% in comparison with ELISA (Table 2). A positive predictive value of 0.77 and negative predictive value of 0.98 was observed with PA in comparison with IgM-capture ELISA.

\section{DISCUSSION}

Generally, JE is diagnosed on the basis of clinical symptoms in developing countries like Nepal. IgM capture ELISA has been the most reliable technique for the confirmatory laboratory diagnosis of JE. But, this technique is expensive and relatively sophisticated. ${ }^{5}$ Laboratory diagnosis of JE is difficult to perform in Nepal due to insufficient resources and diagnostic facilities in many health centers. These shortcomings can be overcome by PA assay.

Out of total 552 serum samples of AES and Viral fever, 258 (47.7\%) were positive for anti-JE IgM by PA assay and 200 (77.5\%) of the 258 PA IgM- positive samples were also IgM positive for anti-JE. IgM by IgM-capture ELISA $(\mathrm{P}<0.05)$ (Table 2$)$. There was significant association between PA and IgM capture ELISA. Thus, PA assay had a sensitivity of $97.5 \%$ and specificity of $83.3 \%$ in comparison with IgM-capture ELISA. A positive predictive value of 0.77 and negative predictive value of 0.98 was observed with PA in comparison with IgM-capture ELISA. Fifty eight (22.5\%) of the 258 PA IgMpositive samples were IgM negative by IgMcapture ELISA. Five samples which were IgM negative for anti-JE IgM by PA were positive by IgM capture ELISA (Table 2). Two hundred eighty nine serum samples were negative for anti-JE IgM by both IgM-capture ELISA and PA assay. These results suggest that PA assay was highly compatible with IgM capture ELISA.

The PA assay does not require specific equipment and is relatively economical, so it would be beneficial for the health centres with limited facilities and where trained personnel are not available. We applied the PA assay to the serum samples collected in Nepal. The sensitivity and specificity of the PA assay is highly compatible with IgM-capture ELISA which was in accordance with the previous study. ${ }^{3,4}$ The sensitivity and specificity were $99 \%$ and $88 \%$ respectively, a positive predictive value of 0.82 and a negative predictive value of 0.99 for PA in comparison with IgM-capture ELISA. $^{3}$

Cross-reactivity of anti-flaviviral IgG has been well 
documented; however, IgM is known to be specific and does not have cross reactivity with other flavivirus. ${ }^{7}$ The data suggest that the PA assay for JEV IgM is rapid, easy to perform and specific. This assay system is useful especially in the rural areas of Asia to support the clinical diagnosis, management, and epidemiological studies of JE. ${ }^{3}$

\section{CONCLUSIONS}

The result from PA was highly compatible with IgM capture ELISA. Both sensitivity and specificity of PA was acceptable in comparison with IgM-capture ELISA. Thus, PA is used as useful diagnostic test for diagnosis of JEV infections in rural hospitals and primary health care centers of Nepal.

\section{ACKNOWLEDGEMENTS}

We would like to thank Everest International Clinic and Research Center, Kalanki, Kathmandu, Nepal for providing laboratory facilities and required reagents. We also would like to thanks Dr. Durga Datt Joshi for providing ELISA reader and equally thankful to all the staffs of Tribhuvan University Teaching Hospital, Lumbini Zonal Hospital, and Bheri Zonal Hospital of Nepal.

CONFLICT OF INTEREST: None to declare.

FINANCIAL INTEREST: None to declare.

\section{REFERENCES}

1. World Health Organization. Japanese encephalitis vaccine: WHO position paper. Wkly Epidemiol Rec 1998;73:337-344.

2. Bista MB, Bastola SP, Shrestha SB, Gautam P. Japanese encephalitis in Nepal (1993-1997): Epidemiological analysis and review of literature. Epidemiology and Disease Control Division (EDCD), Kathmandu, Nepal: Department of Health services (DoHS), Ministry of Health and Population (MoHP), 1999.

3. Pandey BD, Yamamoto A, Morita K, Kurosawa Y, Rai SK, Adhikari S. Serodiagnosis of Japanese encephalitis among Nepalese patients by particle agglutination assay. Epidemiol Infect 2003;131:881-885.

4. Pandey BD, Pun R, Pant KP. Use of particle agglutination assay in the diagnosis of Japanese encephalitis and dengue. Nepal J Sci Technol 2010; 11:189-192.

5. Yamamoto A, Nakayama $M$, Tashiro $M$, Ogawa $T$, Kurane I. Hydroxyapatite-coated nylon beads as a new reagent to develop a particle agglutination assay system for detecting Japanese encephalitis virus - specific human antibodies. J Clin Virol 2000;9:195-204.

6. Yamamoto A, Nakayama M, Kurosawa Y, et al.
Development of a particle agglutination assay system for detecting Japanese encephalitis virus-specific human IgM, using hydroxyapatite-coated nylon beads. J Virol Methods 2002;104:195-201.

7. Burke D, Nisalak A. Detection of Japanese encephalitis virus immunoglobulin $\mathrm{M}$ antibodies in serum by antibody capture radioimmunoassay. Clin Microbiol 1982;15:353-361.

\section{Citing this article}

Pant KP, Pun R, Khanal SR et al. Evaluation of particle agglutination assay for the rapid diagnosis of japanese encephalitis infection. Int J Infect Microbiol 2012;1(1):20-23. 